\title{
Conservation challenges of a sink: the viability of an isolated population of the Snowy Plover
}

\author{
LUKE J. EBERHART-PHILLIPS and MARK A. COLWELL
}

\section{Summary}

Source-sink dynamics are easily overlooked when formulating recovery objectives for threatened species. This could lead to unrealistic criteria imposed on sink populations, which in turn might restrict an entire metapopulation from being delisted. Therefore, an understanding of the viability of subpopulations within the context of a metapopulation is needed to develop appropriate recovery objectives. Consequently, we used II years of mark-recapture, productivity, and movement data to analyse the viability of a small, geographically isolated population of the Snowy Plover Charadrius nivosus, a shorebird listed as threatened under the U.S. Endangered Species Act. Simulations confirmed that the focal population in northern California is a sink that relies upon immigrants from neighbouring populations. Furthermore, these source populations will increase within the next 50 years and are likely to achieve the delisting requirements. However, the northern California population is unlikely to reach the delisting criteria given the current vital rate estimations. Management scenarios demonstrated that lethal predator removal and reducing human disturbance facilitate population recovery and may partially alleviate the reliance upon immigration. However, the use of nest exclosures reduced population growth because they are known to compromise adult survival. These results highlight the importance of maintaining viable source populations and re-evaluating the recovery objectives of metapopulations with active sinks.

\section{Introduction}

Formulating a recovery plan for an endangered species requires a thorough understanding of sourcesink dynamics because unidentified sink populations may delude management into imposing unachievable delisting requirements (Pulliam 1988). This could ultimately lead to sink populations preventing a species from being delisted even if surrounding source populations have met recovery requirements and are viable. Therefore an understanding of the viability of sink populations within the context of source populations is needed to develop appropriate metapopulation conservation objectives (Harveson et al. 2004). An accurate assessment of viability requires long-term data capturing environmental variation across all life history stages (White 2000). In the past, this data requirement had been lacking for many endangered species, but recent efforts to collect vital rate data and improve databases offer the opportunity to evaluate the recovery potential and viability of populations with greater confidence. This is especially the case for shorebirds (suborder Charadrii), which can be banded and monitored relatively easily to estimate survival, reproductive success, and dispersal using mark-recapture methods (Sandercock 2003).

We conducted a population viability analysis (PVA) on a small, geographically isolated population of the Snowy Plover Charadrius nivosus that breeds in coastal northern California. The Snowy Plover (hereafter "plover") is a small shorebird whose listed population segment along the Pacific Coast of the United States extends from southern Washington to the Mexico border in southern California (USFWS 2007). The plover mating system has been described as serial polygamy, 
because both sexes acquire new mates for the second or third successful breeding attempt over the six month breeding season, which begins in March and ends in September (Warriner et al. 1986). Female plovers lay a clutch of three eggs that are incubated for $\sim 28$ days (Warriner et al. 1986). Upon hatching, females usually leave males to search for another mate, while males provide parental care of the brood; as a result, males father a maximum of six young in two broods each season (Warriner et al. 1986). In northern California, plovers are partial migrants, with a proportion of the subpopulation residing year-round and another proportion either wintering or breeding (Colwell et al. 2007). Permanent emigration has been documented to occur as far as $790 \mathrm{~km}$ from natal sites but most yearlings disperse much shorter distances to their first breeding site (Colwell et al. 2007, Stenzel et al. 2007, Pearson and Colwell 2013).

The United States Fish and Wildlife Service (USFWS) listed the Pacific Coast metapopulation of the Snowy Plover as threatened under the United States Endangered Species Act in 1993. The species' Recovery Plan (USFWS 2007) identified three factors that are thought to limit recovery via negative effects on breeding productivity: I) predation of eggs, chicks, and adults by native and introduced vertebrates, 2) encroachment of invasive vegetation such as European beach grass Ammophila arenaria, which degrades breeding habitats, and 3) human activity, which causes direct mortality of eggs, chicks, and adults or indirectly affects the distribution of plovers.

Nur et al. (1999) produced a PVA that assessed the demographic response of the plover metapopulation to 19 scenarios that perturbed vital rates such as adult and juvenile survival, reproductive success, and dispersal. The results of this PVA provided guidance for the formulation of delisting criteria published in the species' recovery plan (USFWS 2007). The recovery objective for the metapopulation was 3,00o breeding adults, with 150 needed in Recovery Unit 2 of coastal northern California (which includes Mendocino, Humboldt, and Del Norte counties; USFWS 2007).

The northern California population has been described as a sink by Mullin et al. (2010), who used an algebraic assessment of population growth using estimates of survival and productivity. We utilised II years of survival and productivity data collected from northern California and elsewhere along the Pacific Coast to assess the viability of the northern California population within the context of surrounding source populations. Our study had two main objectives pertaining to the viability of the northern California population: 1 ) to evaluate the relative importance of specific aspects of plover life history, and 2) to examine various management strategies that address the limiting factors of predation, habitat loss, and human disturbance. With these results, we evaluated the likelihood of population recovery given the current delisting requirements and made management recommendations specific to the northern California population that highlighted the importance of source-sink dynamics operating in the Pacific Coast metapopulation.

\section{Study area}

We monitored a colour-marked population of plovers from 2001 to 2011, on gravel bars of the Eel River and ocean-fronting sandy beaches in Humboldt County, California (Colwell et al. 2010). On beaches, plovers occupied habitat composed of fine homogeneous substrates littered with natural and human debris, and vegetated with large expanses of introduced European beach grass or small restored tracts of native flora. On gravel bars, plovers bred amidst heterogeneous substrates littered with driftwood and vegetated with sparse stands of willow Salix spp. and white sweet clover Melilotus alba. Colwell et al. (2010) provided a detailed description of the study area and the distribution of plovers within these habitats.

\section{Methods}

\section{Field methods}

The population we studied has been intensively monitored each year, with nearly all adults and chicks colour-marked (Colwell et al. 2010, Mullin et al. 2010). Between mid-March and 
mid-August, observers regularly surveyed known breeding sites and suitable breeding habitats; survey frequency increased when observers detected plovers at a site (Colwell et al. 2010). During surveys, observers resighted marked individuals, monitored nests, and determined parenthood based on multiple observations of banded plovers near the nest, adults incubating eggs, or tending chicks (Colwell et al. 2010). Observers conducted research under federal, state, and university permits.

\section{Modelling population viability}

We assessed population viability using VORTEX, version 9.99b (Lacy et al. 2003), a stochastic simulation software package. To investigate source-sink dynamics, we modelled northern California population viability by defining two subpopulations (Figure 1 ). The focal population was Recovery Unit 2 (hereafter "northern California"); neighbouring populations of Oregon, San Francisco Bay, and Monterey Bay constituted a single source population (hereafter "Pacific Coast"), which produce most immigrants to northern California (M. A. Colwell unpubl. data). VORTEX is an individual-based model that tracks the simulated fate of an individual through its lifetime (birth, survival, reproduction, movement, and death; Figure 2). VORTEX simulated population dynamics stochastically by drawing the annual success and fate of each individual from vital rate distributions we estimated and provided in the model (Table $\mathrm{S}_{\boldsymbol{I}}$ in the online Supplementary Materials). VORTEX also required basic plover life history information such as clutch size, mating system, longevity, etc., which we obtained from published literature (Table SI). We used $n=5$ as the quasi-extinction threshold. Therefore, we assumed that if the population declined to five individuals it would result in a major change in management practices (e.g. captive

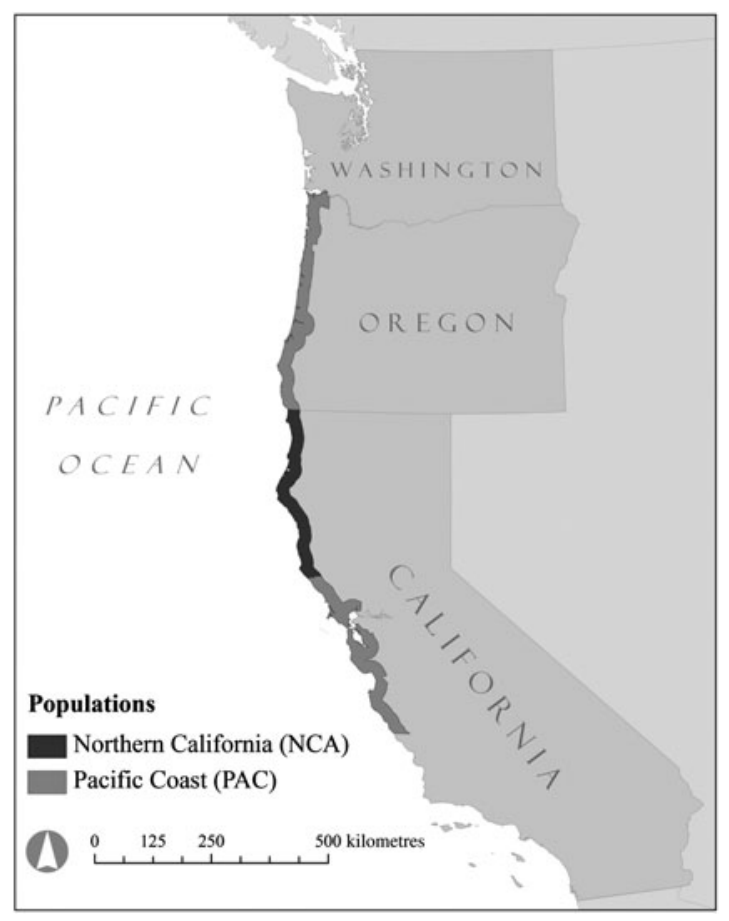

Figure 1. Map of Snowy Plover distribution along the Pacific Coast of the United States with the delineation of the two populations used in the stochastic model. NCA is the northern California focal population and PAC is a source population consisting of surrounding recovery units contributing immigrants to northern California. 


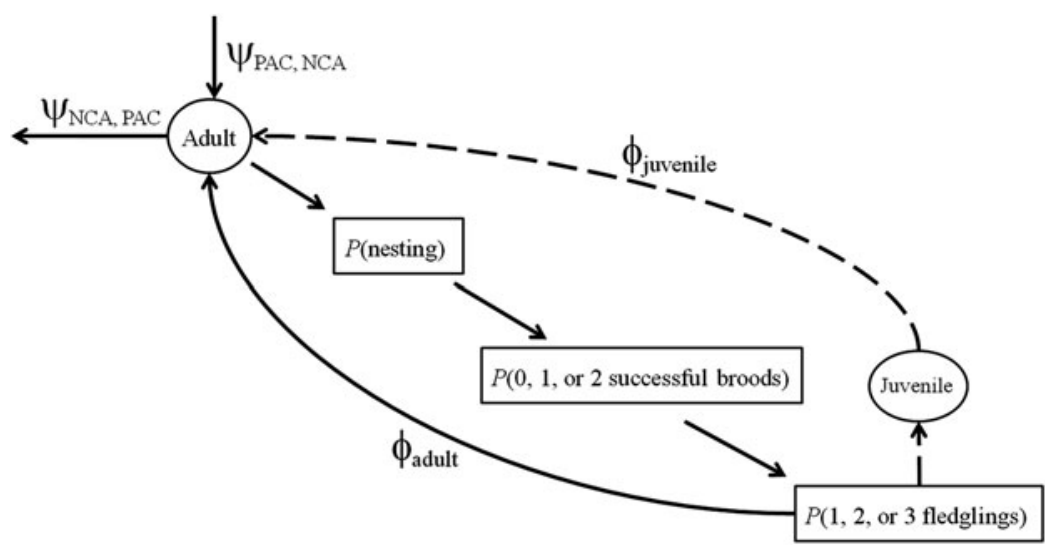

Figure 2. Sequence of life-history events and probabilities $(P)$ used by VORTEX to model population growth of Snowy Plovers in northern California (NCA) in the context of the Pacific Coast population (PAC), where $\phi_{i}$ is the survival of age class $i$ and $\psi_{j, k}$ is the movement between population $j$ and population $k$.

breeding). We projected simulations for 50 years and ran 1000 iterations per simulation to obtain accurate measures of stochastic population dynamics (Caswell 2001).

\section{Vital rate estimation}

We used II years (2001 to 2011) of mark-resight and individual lifetime reproductive success data from northern California to estimate annual apparent survival, productivity, and movement parameters (Figure 2). We defined the resighting interval as the breeding season (i.e. interval over which pairs initiated clutches), a period extending from 15 March to 20 July (M. A. Colwell unpubl. data). See Table $S_{2}$ in the supplementary materials for methods used to estimate plover vital rates.

\section{Evaluating population viability}

Long-term population growth is best predicted by the arithmetic mean of the population growth rates of many simulated iterations, known as the stochastic growth rate $\left(\hat{\mathrm{r}}_{\mathrm{S}}\right.$; Morris and Doak 2002). To quantify the viability of the northern California plover population, we evaluated the $\hat{r}_{S}$ based on 1,000 iterations each simulated for 50 years. The units of $\hat{r}_{S}$ are the number of individuals gained or lost per individual per year, with positive and negative values describing an increase and decrease in the population, respectively.

There have been no studies assessing carrying capacity or density dependence in Snowy Plovers across the study area, and thus it was difficult to consider its role in population viability. Nur et al. (1999), assumed a carrying capacity of 200 for northern California in their coast-wide PVA. Biologically this value may not be realistic, as plovers breed at low density (Page et al. 1983) and there appears to be plenty of unoccupied breeding and wintering habitat available in northern California (Brindock and Colwell 2011, Burrell and Colwell 2012). Nevertheless, we kept the carrying capacity consistent with Nur et al. (1999) because the delisting requirement of 150 individuals for northern California was based on their findings.

The baseline model included vital rate distributions observed in both populations from 2001 to 2011. We evaluated the accuracy of the baseline model by comparing the coefficient of variation in population size observed between 2001 and 2011 with the $95 \%$ confidence interval of the mean coefficient of variation simulated across 30 ten year iterations, using the 2001 counts as the initial population sizes $\left(N_{\mathrm{NCA}}=57, N_{\mathrm{PAC}}=437\right)$. 


\section{Elasticity analysis for stochastic population growth}

A common approach to determine the extent to which vital rates affect population dynamics is to conduct an elasticity analysis, which quantifies the relative change in stochastic population growth resulting from a change in a vital rate (Morris and Doak 2002). To estimate the elasticity of vital rates, we perturbed the vital rates of the baseline model by 10,20 , and $50 \%$ in the direction that would most likely increase $\hat{\mathrm{r}}_{\mathrm{S}_{\mathrm{NCA}}}$. We calculated elasticities as the proportional increase in $\hat{\mathrm{r}}_{\mathrm{S}_{\mathrm{NCA}}}$ divided by the proportional change in the vital rate (Morris and Doak 2002), a method commonly used to calculate elasticities in PVAs (Benton and Grant 1999, Finkelstein et al. 2010, Hudgens et al. 2011).

\section{Assessment of limiting factors}

We developed hypothetical scenarios that evaluated the effectiveness of methods managing one or a combination of the three limiting factors affecting plover viability as identified by the recovery plan (USFWS 2007). Additionally, we assessed the influence of a prolonged cold winter weather catastrophe on population viability and recovery. We evaluated the results of these scenarios by comparing the $\hat{\mathrm{S}}_{\mathrm{S}_{\mathrm{NCA}}}$ to that of the baseline model.

\section{Predation}

Predation of eggs and chicks by Corvus brachyrhynchos and C. corax is the most influential factor affecting Snowy Plover productivity in northern California (Burrell and Colwell 2012). Lethal predator removal and nest exclosures are two methods used to increase productivity that have been implemented at other populations across the Pacific Coast (USFWS 2007). Nest exclosures were used on 135 occasions in northern California between 2001 and 2006 and twice in 2010, and were designed to keep predators from eating eggs. There was no lethal removal of predators in northern California between 2001 and 2011. We simulated two scenarios that utilised lethal predator removal or nest exclosures in northern California to evaluate how these two methods may influence population viability. We implemented this by substituting the relevant northern California vital rates with those of the Pacific Coast where lethal predator removal has been practiced and nest exclosures were used to protect eggs and enhance hatching success since 2002 (unpubl. data from: D. J. Lauten et al., Oregon Biodiversity Information Center; G. W. Page et al., Point Reyes Bird Observatory; C. Robinson-Nilson et al., San Francisco Bay Bird Observatory). Likewise, to assess the use of only nest exclosures, we used northern California productivity rates estimated from 2001 to 2006 productivity data. In northern California, although nest exclosures are shown to increase chick fledgling rates (Watts et al. 2012), they are known to compromise the survival of incubating adults (Hardy and Colwell 2008). To acknowledge this, we used survivorship vital rates estimated between 2001 and 2006 in northern California.

\section{Habitat loss}

The invasion of European beach grass has decreased the amount and quality of plover breeding habitat by increasing beach slope and creating less open space (Wiedemann 1987, Muir and Colwell 2010). Agencies occasionally restore plover habitat by removing European beach grass, which enhances recovery of the native dune ecosystem. With the creation of open habitat, we assumed that carrying capacity increased (USFWS 2007). To assess the influence of habitat restoration on population viability in northern California, we ran six management scenarios of the stochastic simulation that perturbed the baseline carrying capacity $(K=200)$ in both directions by 10,20 , and $50 \%$.

\section{Human activity}

Human activity compromises plover productivity (Ruhlen et al. 2003, Lafferty et al. 2006, Wilson and Colwell 2010) and survival (Brindock and Colwell 2011), and affects the distribution of plovers 
on a beach (Lafferty et al. 2006). Fencing, consisting of a roped boundary with signs posted to inform the public that the delineated area is restricted, is commonly used to reduce human disturbance (USFWS 2007). In northern California, plover fledging success was almost twice as high within a fenced area than outside the fence (Wilson and Colwell 2010). Additionally, Lafferty et al. (2006) observed a more than $50 \%$ reduction in disturbance events after the installation of a fence. Survival may be compromised by human activities, such as driving vehicles through wintering flocks and occasionally killing plovers (Brindock and Colwell 2011).

We assessed the response of the population to a reduction in human disturbance by simulating scenarios in which we matched productivity distributions to those observed inside fencing (Wilson and Colwell 2010) and increased the survival of adults and juveniles by $2 \%, 5 \%$ or $10 \%$. There are no data to quantitatively assess how varying levels of vehicle use on beaches reduces plover survival probability, therefore we used a range of perturbations that we believe is conservative given anecdotal reports of shorebird mortality associated with vehicle strikes elsewhere within the winter range on the plover (Buchanan 2011).

\section{Severe winter weather}

Severe weather, such as low temperature anomalies, can reduce the over-winter survival of shorebirds (Parr 1992, Yalden and Pearce-Higgins 1997, Durell et al. 2006, Roche et al. 2010) and plovers in northern California (Eberhart-Phillips 2012). Estimates from the vicinity of Monterey Bay indicate especially low overwinter juvenile and adult survival in 1987 and 1998 (Stenzel et al. 2007, 2011), which may be related to climatic events like the winter of 1998 during which there were seven consecutive days with a minimum temperature at or below freezing.

Severe winter weather catastrophes were estimated to reduce survival by $26 \%$ in northern California and by $7 \%$ in the Pacific Coast, with a $15 \%$ probability of occurring in any one year (Eberhart-Phillips 2012). We used these catastrophe statistics as parameters in VORTEX to simulate the influence of a catastrophe on the viability of the northern California plover population.

\section{Results}

\section{Vital rate estimation}

At the end of the 2011 breeding season, our dataset included 224 males and 244 females; 176 were immigrants originating from the Pacific Coast, 64 were recruited locally within northern California, and 228 were individuals that hatched in northern California but did not return in subsequent breeding seasons. Table $\mathrm{S}_{3}$ gives results pertaining to plover vital rate estimates.

\section{Modelling}

The observed coefficient of variation in population size between 2001 and 2011 (NCA $=0.366$, $\mathrm{PAC}=0.207)$ fell within the $95 \%$ confidence intervals of the coefficient of variation of the 2001 to 2011 baseline model $\left(\widehat{C V}_{\mathrm{NCA}}=0.377,95 \% \mathrm{CI}=0.310\right.$ to $0.443 ; \widehat{\mathrm{CV}}_{\mathrm{PAC}}=0.229,95 \% \mathrm{CI}=0.200$ to 0.258$)$, demonstrating that the structure of the baseline model accurately predicted the observed stochasticity. The observed trend of northern California deviated positively from the simulated projection between 2001 and 2006, but between 2007 and 2011 the model effectively predicted the observed trend (Figure 3a). Between 2001 and 2011, the simulated projection of the Pacific Coast population slightly underestimated the observed population size, but the observed trend fell within the $95 \%$ confidence interval of the simulation's average projection for all years (Figure $3 \mathrm{~b}$ ).

When we projected the model into the future using the 2011 counts as the initial population sizes $\left(N_{\mathrm{NCA}}=36, N_{\mathrm{PAC}}=799\right)$, the baseline model experienced slightly positive growth $\left(\hat{\mathrm{r}}_{\mathrm{S} \mathrm{Nat}}=0.008 \pm 0.248 \mathrm{SD}\right)$ such that by the fiftieth year, northern California had an average of 59 individuals with a $0.2 \%$ probability of quasi-extinction (Figure $3 \mathrm{c}$ ). Similarly, the baseline 

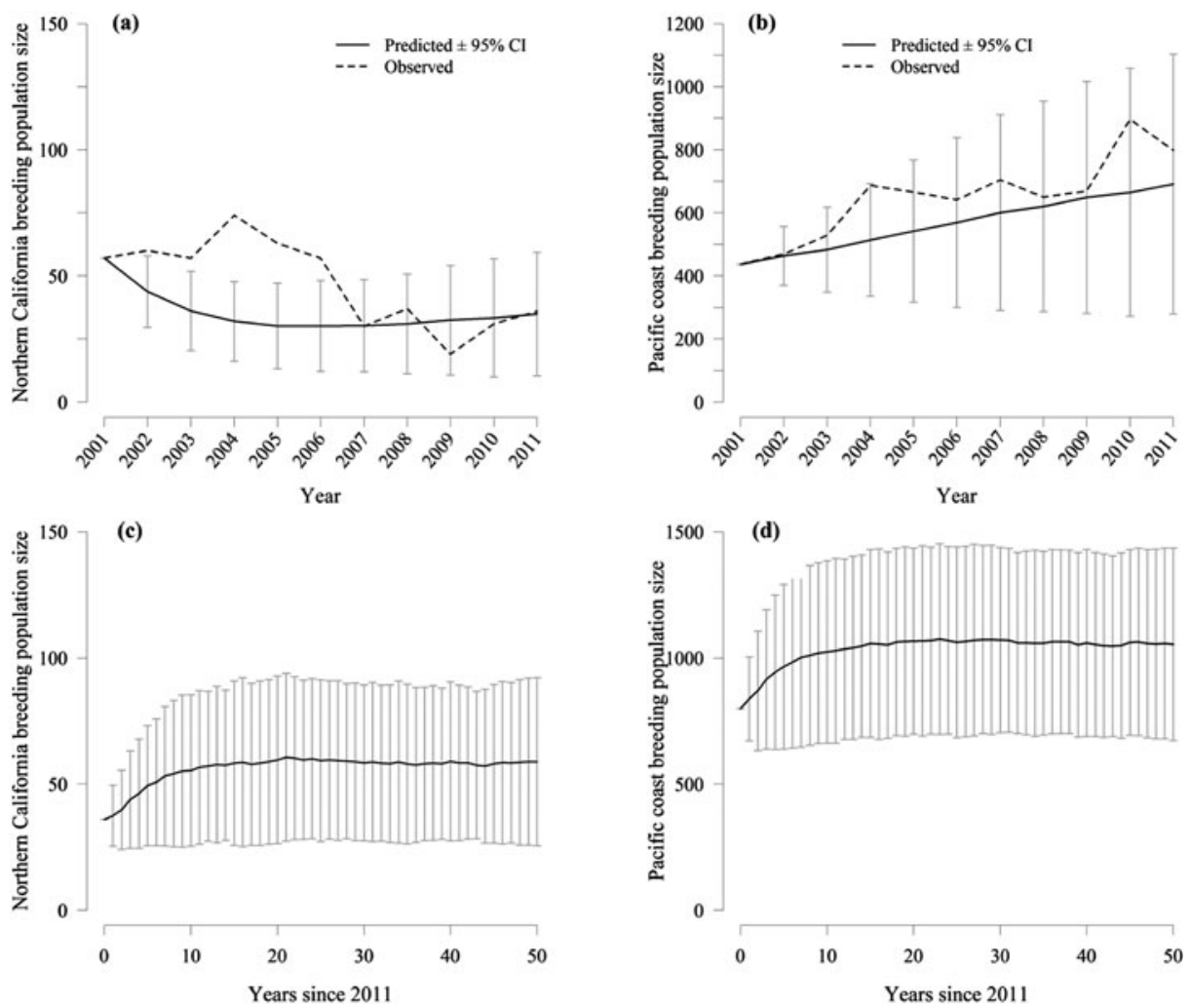

Figure 3. Comparison of observed and predicted population projections for (a) northern California and (b) the Pacific Coast between 2001 and 2011 using the 2001 initial population sizes and the baseline vital rates. Baseline model population projections for (c) northern California and (d) the Pacific Coast. Error bars represent the $95 \%$ confidence interval of the average population size of 1,000 iterations.

model of the Pacific Coast exhibited positive growth $\left(\hat{\mathrm{r}}_{\mathrm{S}_{\mathrm{PAC}}}=0.035 \pm 0.147 \mathrm{SD}\right.$; Figure $\left.3 \mathrm{~d}\right)$ and increased to an average of 1054 individuals after 50 years with a $0 \%$ probability of quasi-extinction.

The elasticity of $\hat{r}_{S_{\mathrm{SCA}}}$ was greater for perturbations of Pacific Coast vital rates than for perturbations in the vital rates of northern California, with the productivity of the Pacific Coast having the largest influence on $\hat{\mathrm{S}}_{\mathrm{S} \mathrm{NCA}}$ (Figure 4). For example, a 10\% increase in the expected brood and fledging parameters of the Pacific Coast increased the $\hat{\mathrm{r}}_{\mathrm{S}_{\mathrm{NCA}}} 1.81$ times more than a $50 \%$ increase in northern California adult survival, 10 times more than a $50 \%$ increase in the expected brood and fledging parameters of northern California, and 20 times more than a $50 \%$ increase in the carrying capacity of northern California.

Immigration was an important component of the model. A $20 \%$ increase in the immigration rate had a greater effect on northern California growth than all other northern California productivity vital rates (Figure 4). A scenario in which no movement occurred between the two populations resulted in $100 \%$ probability of quasi-extinction of northern California after an average of five years and a $46 \%$ increase in growth for the Pacific Coast population $\left(\hat{\mathrm{r}}_{\mathrm{PAC}_{\mathrm{C}}}=0.051 \pm 0.146 \mathrm{SD}\right)$.

Our estimate of northern California juvenile apparent survival $\left(\hat{\phi}_{\text {Iuvenile }}=0.23 \pm 0.09\right)$ was $50 \%$ of the true juvenile survival estimated in Monterey Bay $\left(\mathrm{S}_{\text {Iuvenile }}=0.46 \pm 0.07\right)$ by Stenzel et al. $(2007)$. This suggests our estimate of juvenile apparent survival in northern California was biased low because it is confounded with permanent emigration (Sandercock 2003). To evaluate the relative difference in 


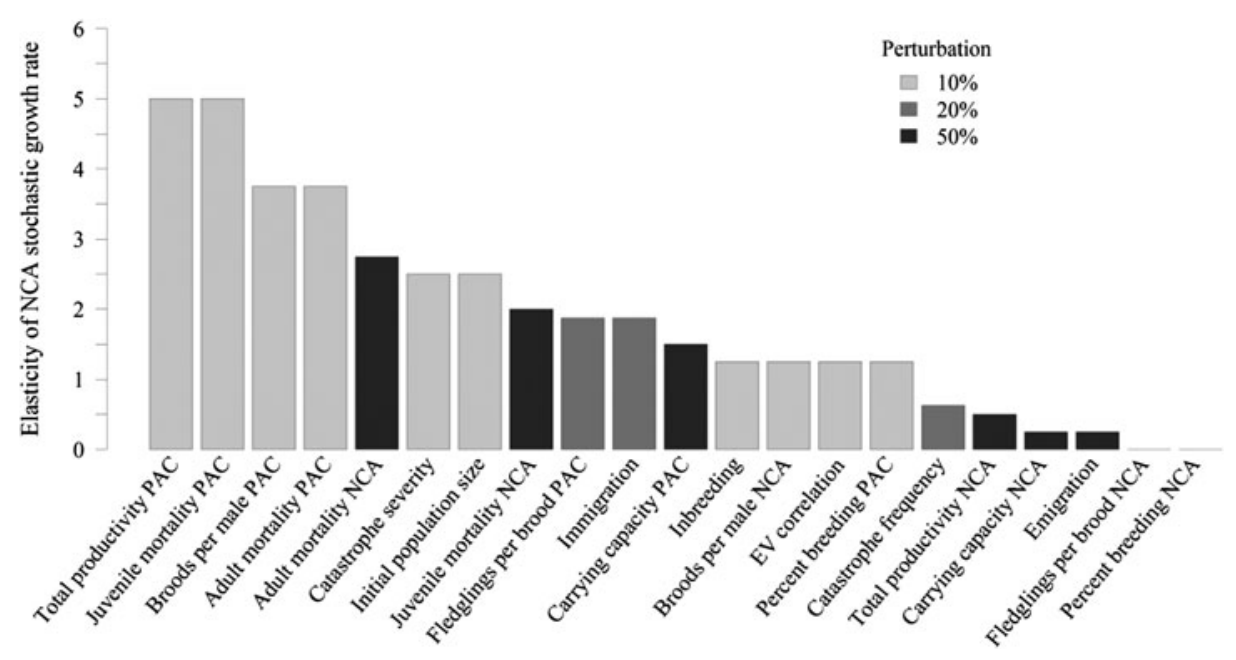

Figure 4. Elasticity of the stochastic growth rate of the northern California population for 21 model components specific to northern California (NCA), the Pacific Coast (PAC), or globally affecting both populations simultaneously (immigration, emigration, the winter cold weather catastrophe, and inbreeding). Total productivity represents a perturbation of both the broods per male and fledglings per brood distributions. All perturbations were made in the direction that would hypothetically favour growth in northern California.

the two estimates of juvenile survival, we simulated a model in which juvenile survival and variation of northern California was equal to that of the Pacific Coast. This resulted in a $50 \%$ increase in the growth of northern California over the baseline $\left(\hat{r}_{S_{\mathrm{NCA}}}=0.012 \pm 0.23 \mathrm{SD}, \mathrm{N}_{50}=72\right)$; however, the delisting criterion of 150 breeding adults was not achieved within the 50 -year simulation.

\section{Assessment of limiting factors}

\section{Nest and brood predation}

To simulate the use of lethal predator removal in northern California, we increased the expected successful broods per breeding male from 0.44 to 0.84 and the expected fledglings per successful brood from 1.82 to 1.87 , which were the productivity rates observed across the Pacific Coast where such management has been practiced. This simulation resulted in a $25 \%$ increase in the growth of northern California over the baseline. However the population did not reach the recovery objective of 150 individuals $\left(\hat{r}_{S_{\text {NCA }}}=0.01 \pm 0.262 \mathrm{SD}, \mathrm{N}_{50}=68\right.$; Figure $\left.5 \mathrm{a}\right)$.

Likewise, to simulate the use of nest exclosures we increased the expected successful broods per breeding male from 0.44 to 0.54 and decreased adult survival from 0.62 to 0.57 , which were the brood and survival rates observed and estimated in northern California between 2001 and 2006 when nest exclosures were used. This simulation resulted in a $12.5 \%$ decrease in the growth of northern California $\left(\hat{\mathrm{S}}_{\mathrm{S}_{\mathrm{NCA}}}=0.007 \pm 0.255 \mathrm{SD}\right.$ ) over the baseline (Figure $5 \mathrm{~b}$ ).

\section{Habitat loss}

All perturbations of carrying capacity in northern California that simulated habitat restoration did not result in a difference in $\hat{\mathrm{r}}_{\mathrm{S}_{\mathrm{N} C}}$ from the baseline. However, increasing the carrying capacity of the Pacific Coast by 10\% from 1,300 to 1,450 individuals resulted in a $12.5 \%$ increase in the growth in northern California. 

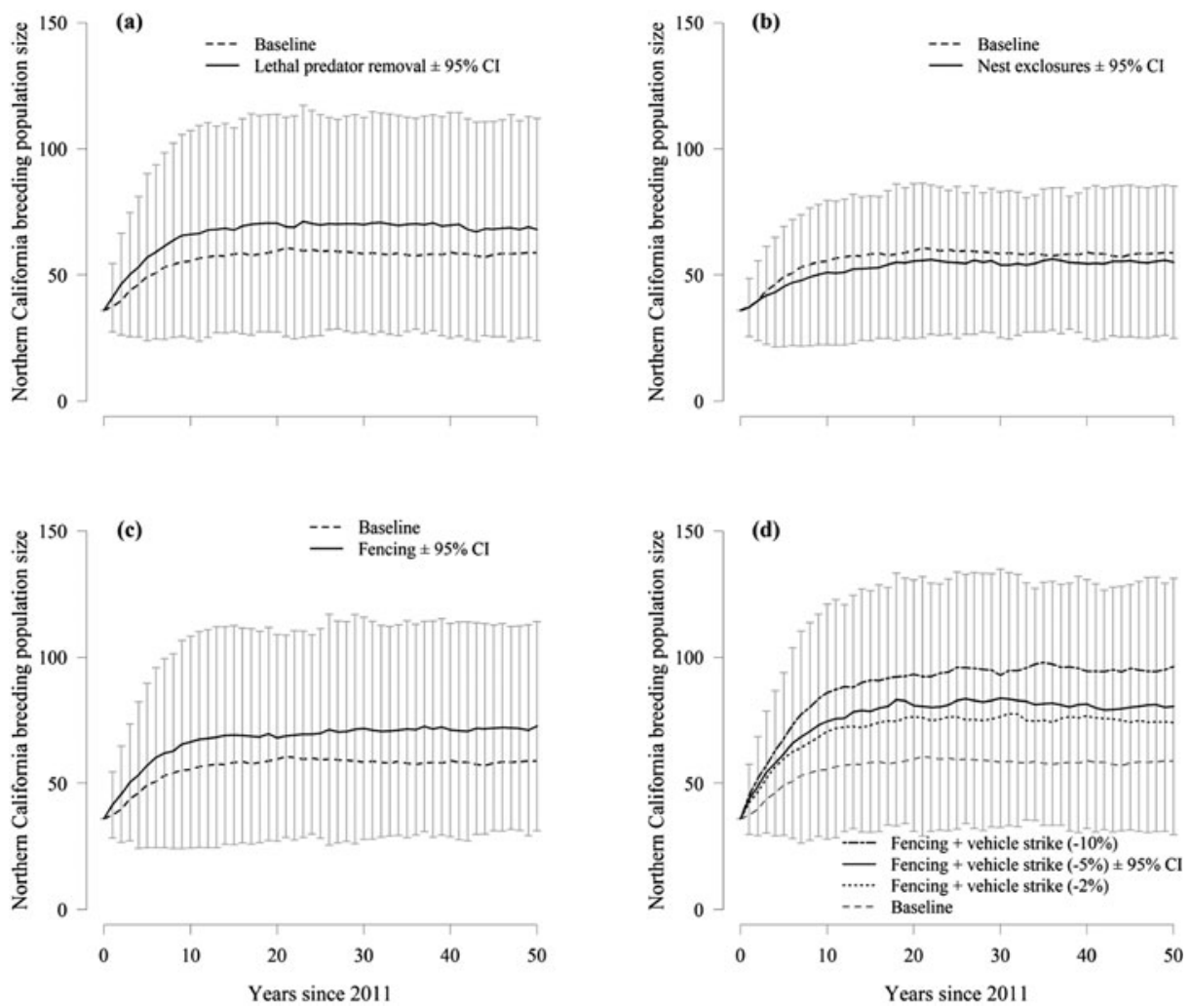

Figure 5. Population projections for northern California under four management approaches addressing either predation or human disturbance: (a) lethal predator removal, (b) the use of nest exclosures, (c) fencing, and (d) fencing with three levels of hypothetical reductions in mortality related to vehicle strike. Error bars represent the $95 \%$ confidence interval of the average population size of 1,000 iterations.

\section{Human disturbance}

We assessed management of human disturbance using two models. The first model simulated a doubling in productivity through the use of fencing throughout all suitable breeding habitat in northern California. This model differed from the current management regime, which has used fencing sparingly at a few sites. Doubling productivity resulted in a $50 \%$ increase in the growth of northern California $\left(\hat{\mathrm{r}}_{\mathrm{S}_{\mathrm{NCA}}}=0.012 \pm 0.257 \mathrm{SD}\right.$ ) from that of the baseline (Figure $5 \mathrm{c}$ ).

The second model simulated the use of fencing and prohibition of recreational vehicle use near known plover habitat. We simulated this management scenario by using the productivity rates of the first model and by increasing adult and juvenile survival by $2 \%, 5 \%$ or $10 \%$. With fencing and a $2 \%$ increase in survival, there was a $50 \%$ increase in the population growth $\left(\hat{\mathrm{S}}_{\mathrm{S}_{\mathrm{NCA}}}=0.012 \pm 0.255 \mathrm{SD}\right)$ over the baseline (Figure $5 \mathrm{~d}$ ). However with fencing and a $10 \%$ increase in survival, there was a $140 \%$ increase in the baseline growth of northern California $\left(\hat{\mathrm{r}}_{\mathrm{S}_{\mathrm{NCA}}}=0.019 \pm 0.244 \mathrm{SD}\right.$; Figure $\left.5 \mathrm{~d}\right)$.

\section{Severe winter weather}

The severity of the cold winter catastrophe was an important component of the model. A 10\% reduction in severity had a greater elasticity than all perturbations of northern California vital rates, except 
a $50 \%$ reduction in adult mortality (Figure 4). Reducing the catastrophe severity by $10 \%$ resulted in a $25 \%$ increase in the growth of northern California $\left(\hat{\mathrm{r}}_{\mathrm{S}_{\mathrm{NCA}}}=0.01 \pm 0.239 \mathrm{SD}\right)$. The elasticities of northern California growth to perturbations in the frequency of catastrophes were not as important as those of the severity (Figure 4). A 50\% reduction in the frequency resulted in a $12.5 \%$ increase in growth over the baseline $\left(\hat{\mathrm{r}}_{\mathrm{SCA}}=0.009 \pm 0.246 \mathrm{SD}\right)$. Removing the catastrophe from the model resulted in a $37.5 \%$ increase in population growth in northern California $\left(\hat{\mathrm{r}}_{\mathrm{S}_{\mathrm{NCA}}}=0.011 \pm 0.230 \mathrm{SD}\right)$.

\section{Discussion}

Four main findings emerged regarding the viability of the plover subpopulation in northern California: 1 ) the population is a sink that relies upon immigrants originating from adjacent populations; 2) population persistence depends on continued management aimed at increasing plover productivity at source populations elsewhere on the Pacific Coast; 3) local management should consider the risks associated with the use of nest exclosures and acknowledge the benefits of reducing human disturbance and implementing predator removal; and 4) decreased survival associated with cold winter weather strongly influenced population growth.

\section{Model performance}

Baseline projections forecasting 50 years indicated that both the northern California and Pacific Coast populations will increase. The structure of the baseline model reflected the observed stochasticity accurately; however, the simulated trajectory of northern California underestimated the observed population size between 2001 and 2006. The shortfall of the model between 2001 and 2006 most likely resulted from two things. First, the 2001-2006 interval did not experience winters with prolonged cold weather (Eberhart-Phillips 2012); whereas on average, simulations included one or more catastrophic winters during this interval which depressed simulated growth rates. Second, productivity parameters of the baseline model were based upon productivity data averaged over the entire 11-year period; whereas between 2001 and 2006, nest exclosures were used to manage nest predators which resulted in higher nest success during that interval.

\section{Population viability}

The productivity and survival rates used in the model do not support a self-sustaining plover population in northern California. Consequently, immigration from source populations elsewhere along the Pacific Coast is necessary to maintain a breeding population in northern California. Our study confirmed the role of immigration in northern California using state-of-the-art methods and updated demographic data. Mullin et al. (2010) classified the northern California population as a sink based on an algebraic assessment of population growth using estimates of productivity and survival. And in the PVA by Nur et al. (1999), when dispersal was reduced to zero, the northern California population became extinct. Plissner and Haig (2000) derived similar conclusions from their PVA of the Atlantic Coast breeding metapopulation of Piping Plovers C. melodus: persistence time increased with increased movement rates and greater connectivity increased the total size of the metapopulation. For Snowy Plovers, this emphasises the importance of dispersal to counterbalance regional low productivity or survival, such as that experienced in northern California (USFWS 2007).

The influence of inbreeding on population growth was relatively low compared to other components of the model. This suggests that during simulations, immigration of individuals from the Pacific Coast replenished genetic variation in northern California, subsequently reducing the impact of inbreeding depression. This phenomenon, known as 'genetic rescue' (Ingvarsson 2001), highlights another reason why immigration is crucial for the viability of the northern California population.

Our estimates of variation in adult and juvenile survival in northern California were greater than those of the Pacific Coast, which meant that simulations of northern California experienced large annual fluctuations in population growth given the high elasticity of adult and juvenile mortality. 
In addition to its low productivity, the large stochasticity of influential vital rates (e.g. survival) characterises the northern California population as a sink. This was further supported by the "no movement" scenario, which demonstrated that the growth of the Pacific Coast population increased by $46 \%$ when immigration to northern California ceased. Viewed another way, the northern California population is a burden to the recovery of the rest of the Pacific Coast metapopulation.

Delisting of the plover requires a metapopulation of 3,00o breeding adults maintained for Io years distributed disproportionately among the recovery units and an average annual productivity of one fledged chick per breeding male for five years (USFWS 2007). Recovery of the northern California population requires 150 breeding adults and Recovery Units 1, 3, and 4 (which make up the Pacific Coast population in this study) collectively require 1,150 breeding adults (USFWS 2007). The Pacific Coast population will likely achieve the delisting requirements within the next 30 years given that the population currently produces an annual average of 1.32 fledged chicks per breeding male and the baseline simulation had an average of $1,060 \pm 269$ SD individuals after 20 years. However, the northern California population is unlikely to reach the recovery objectives given that the population currently produces an annual average of 0.68 fledged chicks per male and the baseline simulation had an average of $60 \pm 23 \mathrm{SD}$ individuals after 20 years. Even those simulations with $50 \%$ reductions in the mortality of adults or juveniles in northern California resulted in insufficient population growth needed to achieve 150 breeding adults. This finding highlights that the delisting of the entire Pacific Coast Snowy Plover metapopulation will likely be precluded by sink populations such as northern California, given the current delisting requirements.

Although northern California is a sink, its persistence may be important for the viability of the entire metapopulation. Howe et al. (1991) argued that a metapopulation with a large proportion of individuals residing in sinks can still be viable. Furthermore, Howe et al. (1991) found through simulations that in many cases sink populations can 1 ) increase the overall size of a metapopulation, 2) increase the size of source populations, and 3) extend the persistence of metapopulations in decline. Howe et al. (1991) argued that sink populations offer available habitat for emigrants from crowded source populations to persist, albeit under conditions that are unsustainable in isolation. Therefore, the protection and maintenance of productive populations such as those in Oregon and Monterey Bay must be a priority for Snowy Plover management, but the preservation of marginal populations such as northern California should still be part of the conservation plan. The 4 (d) rule proposed by the U.S. Department of the Interior (2006) would have allowed regions to relax management if they had met the recovery criteria. However, without a productive source population, the northern California population would likely be pushed to extinction within the next 20 years.

\section{Management of limiting factors}

Management scenarios addressing human disturbance were the most beneficial for the growth of the northern California population. Population growth increased by $50 \%$ through the use of fencing and a further $25 \%$ with the prohibition of recreational vehicle use on beaches (assuming a $5 \%$ reduction in mortality). It is important to note that our fencing scenario assumed that fencing would be implemented across all beaches in northern California, which is unrealistic. However, our results demonstrate the benefits of managing human disturbance. Wilson and Colwell (2010) found that fencing in northern California increased productivity through a reduction in brood movement. Because of human disturbance, chicks that were raised outside of the fenced area travelled greater distances than those raised in it, potentially exposing broods to higher risks of mortality (Wilson and Colwell 2010). The influence of human disturbance on plover productivity in northern California is almost certainly augmented by corvid predation of broods, which coincides with areas of human activity (Marzluff and Neatherlin 2006).

Recreational vehicle use in plover habitat is a complicated issue, considering that there is only anecdotal evidence to support its negative influence on survival in northern California (Brindock and Colwell 2011). However, the potential effects of vehicle use on population growth in northern California must be acknowledged by management because survival, especially that of adults, had the 
greatest effect on plover population growth; this result is common to other shorebirds (Sandercock 2003). This may be especially important during the non-breeding season, when plover survival is likely compromised by severe winter weather (Yalden and Pearce-Higgins 1997, Eberhart-Phillips 2012). It may be politically unfeasible to enforce a coast-wide prohibition of recreational vehicle use on the beaches in northern California, but regional prohibition at locations where plovers predictably over-winter (see Brindock and Colwell 2010) could be an alternative. After a regional ban of vehicle use on beaches in South Africa, Williams et al. (2004) observed a doubling in populations of Crowned Plover Vanellus coronatus, Blacksmith Plover V. armatus, and Sanderling Calidris $a l b a$, suggesting that such management was effective.

Predation of eggs and chicks, mainly by corvids, is the most important factor limiting productivity in northern California (Burrell and Colwell 2012). Simulations demonstrated that managing predation with lethal methods was $43 \%$ more effective at improving population growth in northern California than the use of nest exclosures. The elasticity analysis revealed that the expected number of successful broods per nesting male was the most influential productivity vital rate of northern California affecting growth. This provides support for the use of lethal predator removal in northern California because lethal methods improve both egg and chick survival, whereas exclosures only protect nests and are known to compromise the survival of incubating adults (Hardy and Colwell 2008), the most elastic vital rate. This finding is supported by Watts et al. (2012) who concluded that a 10\% increase in adult mortality resulting from nest exclosures would result in a declining population in northern California.

Habitat restoration scenarios revealed that for the current population size of northern California $\left(N_{2011}=36\right)$, the assumed carrying capacity $(K=200)$ is not restricting population growth. All simulations that perturbed carrying capacity (positively or negatively) did not strongly affect population growth. This finding relies upon the assumption of the model that habitat restoration only increases carrying capacity and not vital rates such as survival and productivity. There is no evidence to suggest an increase in survival associated with habitat restoration; however, restoration may indirectly enhance nest survival through the creation of open habitat which facilitates an early detection of predators by incubating plovers (Koivula and Rönkä 1998). Muir and Colwell (2010) found that breeding plovers selected nest sites that were more open than random sites; however there was no evidence to suggest that restored habitat was of higher quality because measures of enhanced productivity associated with open habitat were not evaluated. Although our findings suggest that habitat restoration is not a priority for the recovery of plovers in northern California, it is important to stress that other species benefit from restoration of the native dune ecosystem.

The simulated cold winter weather catastrophe strongly influenced population growth in northern California and is likely a factor contributing to its status as a sink. Evidence suggests that cold winter anomalies caused decreased survival (Eberhart-Phillips 2012), a vital rate with the highest elasticity in northern California. Winter weather severity was highly variable between 2001 and 2011 and is thus a probable source for the large variation in both adult and juvenile survival observed over the 11-year period (Eberhart-Phillips 2012). Stochastic weather events make small isolated populations like northern California especially vulnerable to extinction (Crick 2004). The influence of climate highlighted by this study provides evidence that factors beyond direct control of humans affect population viability.

Pulliam (1988) argued that sink populations could easily mislead management into formulating unrealistic population size expectations if the underlying source-sink dynamics of the metapopulation were not fully understood. The delisting criteria for plovers in northern California was formulated based upon a metapopulation viability analysis (Nur et al. 1999), that made large assumptions pertaining to population-specific vital rates because of data limitations at the time of analysis. For example, in their model, Nur et al. (1999) included I) higher estimates of adult $\left(\hat{\phi}_{\text {Adult }}=0.76 \pm 0.05\right)$ and juvenile $\left(\hat{\phi}_{\text {Juvenile }}=0.5 \pm 0.07\right)$ survival with less variation, and 2$)$ a catastrophe that reduced productivity by $50 \%$ every 20 years. Nur et al. (1999) also concluded that northern California is a sink; however, the differences between the parameters used in their model and those of this study are a likely source for the differing conclusions regarding an achievable recovery population size in northern California. 
Results of this study draw attention to active source-sink processes working within the Pacific Coast Snowy Plover metapopulation. Managers must collaborate to focus conservation efforts on maintaining viable source populations but not neglect sinks. Our study suggests that some of the delisting criteria in the Snowy Plover Recovery Plan may be unrealistic, which could prevent the Pacific Coast metapopulation from being delisted. However, because this study focused specifically upon northern California, our model was limited to a simple source-sink structure and thus we must be cautious about drawing inferences about the status of other subpopulations and their relationship to surrounding sinks or sources. Therefore, given the coastwide efforts by plover biologists to collect ample vital rate data since the analysis by Nur et al. (1999), we recommend that future work should be focused on a thorough reassessment of metapopulation structure and viability of Snowy Plovers across the Pacific Coast. This will provide valuable information pertaining to the recovery potential of Snowy Plovers given the current delisting requirements.

\section{Supplementary Material}

The supplementary materials for this article can be found at journals.cambridge.org/bci

\section{Acknowledgements}

Many individuals assisted us with fieldwork in northern California; in particular, we thank K. Brindock, N. Burrell, W. Goldenberg, J. Hall, M. Hardy, J. Harris, D. Herman, A. Hoffmann, S. Hurley, R. LeValley, A. Liebenberg, S. McAllister, J. Meyer, C. Millett, S. Mullin, J. Muir, Z. Nelson, A. Patrick, W. Pearson, S. Peterson, K. Ross, K. Sesser, R. Thiem, A. Transou, J. Watkins, and C. Wilson. This study would not be possible without the fieldwork and reports from many biologists across the Pacific Coast; in particular we thank K. Castelein, D. Lauten, G. Page, C. Robinson-Nilson, and L. Stenzel. S. Dinsmore, T. L. George, B. Hudgens, and an anonymous reviewer assisted with revisions of the modelling procedure and provided constructive comments to this manuscript. Field work was funded by the California Department of Fish and Game, California Department of Parks and Recreation, Chevron Oil Corporation, Humboldt State University Sponsored Programs Foundation, Marin Rod and Gun Club, MRB Research, Inc., U.S. Bureau of Land Management, U.S. Fish and Wildlife Service, and California Department of Fish and Game's Oil Spill Response Trust Fund through the Oiled Wildlife Care Network at the Wildlife Health Center, School of Veterinary Medicine, University of California, Davis.

\section{References}

Benton, T. G. and Grant, A. (1999) Elasticity analysis as an important tool in evolutionary and population ecology. Trends Ecol. Evol. 14: 467-471.

Brindock, K. M. and Colwell, M. A. (2011) Habitat selection by western Snowy Plovers during the nonbreeding season. J. Wildl. Manage. 75: 786-793.

Buchanan, J. B. (2011) Collisions and in-flight calamities involving shorebirds in western Washington. Washington Birds I1: 22-27.

Burrell, N. S and Colwell, M. A. (2012) Direct and indirect evidence that productivity of Snowy Plovers Charadrius nivosus varies with occurrence of a nest predator. Wildfowl 62: 202-221.

Caswell, H. (2001) Matrix population models: construction, analysis, and interpretation. 2nd edition. Sunderland, Massachusetts, USA: Sinauer Associates.

Colwell, M. A., McAllister, S. E., Millet, C. B., Transou, A. N., Mullin, S. M., Nelson, Z. J., Wilson, C. A. and LeValley, R. R. (2007) Philopatry and natal dispersal of the western Snowy Plover. Wilson J. Ornithol. 119: $378-385$.

Colwell, M. A., Burrell, N. S., Hardy, M. A., Kayano, K., Muir, J. J., Pearson, W. J., Peterson, S. A. and Sesser, K. A. (2010) Arrival times, 
laying dates and reproductive success of Snowy Plovers in two habitats in coastal northern California. J. Field Ornithol. 81: 349-360.

Crick, H. Q. P. (2004) The impact of climate change on birds. Ibis 146(S1): 48-56.

Durell, S. E. A. Le V. dit, Stillman, R. A., Caldow, R. W. G., McGrorty, S., West, A. D. and Humphreys, J. (2006) Modelling the effect of environmental change on shorebirds: a case study on Poole Harbour, UK. Biol. Conserv. 131: 459-473.

Eberhart-Phillips, L. J. (2012) Population viability of Snowy Plovers in coastal northern California. M.Sc. Thesis, Humboldt State University, Arcata, California, USA.

Finkelstein, M. E., Wolf, S., Goldman, M., Doak, D. F., Sievert, P. R., Balogh, G. and Hasegawa, H. (2010) The anatomy of a (potential) disaster: volcanoes, behavior, and population viability of the short-tailed albatross (Phoebastria albatrus). Biol. Conserv. 143: 321-331.

Hardy, M. A. and Colwell, M. A. (2008) The impact of predator exclosures on Snowy Plover nesting success: a seven-year study. Wader Study Group Bull. 115: 161-166.

Harveson, P. M., Lopez, R. R., Silvy, N. J. and Frank, P. A. (2004) Source-sink dynamics of Florida key deer of Big Pine Key, Florida. J. Wildl. Manage. 68: 909-915.

Howe, R. W., Davis, G. J. and Mosca, V. (1991) The demographic significance of 'sink' populations. Biol. Conserv. 57: 239-255.

Hudgens, B., Beaudry, F., George, T. L., Kaiser, S. and Munkwitz, N. M. (2011) Shifting threats faced by the San Clemente sage sparrow. J. Wildl. Manage. 75: 1350-1360.

Ingvarsson, P. K. (2001) Restoration of genetic variation lost - the genetic rescue hypothesis. Trends Ecol. Evol. 16: 62-63.

Koivula, K. and Rönkä, A. (1998) Habitat deterioration and antipredator strategy in a meadow-breeding wader, Temminck's stint (Calidris temminckii). Oecologia 116: 348-355.

Lacy, R. C., Borbat, M. and Pollak, J. P. (2003) VORTEX: a stochastic simulation of the extinction process. Version 9. Brookfield, Illinois, USA: Chicago Zoological Society.

Lafferty, K. D., Goodman, D. and Sandoval, C. P. (2006) Restoration of breeding by Snowy
Plovers following protection from disturbance. Biodivers. Conserv. 15: 2217-2230.

Marzluff, J. M. and Neatherlin, E. (2006) Corvid response to human settlements and campgrounds: causes, consequences, and challenges for conservation. Biol. Conserv. 130: 301-314.

Morris, W. F. and Doak, D. F. (2002) Quantitative conservation biology: theory and practice of population viability analysis. Sutherland, Massachusetts, USA: Sinauer Associates.

Muir, J. J. and Colwell, M. A. (2010) Snowy Plovers select open habitats for courtship scrapes and nests. The Condor 112: 507-510.

Mullin, S. M., Colwell, M. A., McAllister, S. E. and Dinsmore, S. J. (2010) Apparent survival and population growth of Snowy Plovers in coastal northern California. J. Wildl. Manage. 74: 1792-1798.

Nur, N., Page, G. W. and Stenzel, L. E. (1999) Population viability analysis for Pacific Coast Snowy Plovers. Appendix D. In U. S. Fish and Wildlife Service. 2007. Recovery plan for the Pacific Coast population of the western Snowy Plover (Charadrius alexandrinus nivosus). Two volumes. Sacramento, California, USA: USFWS.

Page, G. W., Stenzel, L. E., Winkler, D. W. and Swarth, C. W. (1983) Spacing out at Mono Lake: breeding success, nest density, and predation in the Snowy Plover. The Auk 1oo: 13-24.

Parr, R. (1992) The decline to extinction of a population of golden plover in north-east Scotland. Ornis Scand. 23: 152-158.

Pearson, W. J. and Colwell, M. A. (2013) Effects of nest success and mate fidelity on breeding dispersal in a population of Snowy Plovers Charadrius nivosus. Bird Conserv. Internatn. In press.

Plissner, J. H. and Haig, S. M. (200o) Viability of piping plover Charadrius melodus metapopulations. Biol. Conserv. 92: 163-173.

Pulliam, H. R (1988) Sources, sinks, and population regulation. Am. Nat. 132: 652-661.

Roche, E. A., Cohen, J. B., Catlin, D. H., Amirault-Langlais, D. L., Cuthbert, F. J., Gratto-Trevor, C. L., Felio, J. and Fraser, J. D. (2010) Range-wide piping plover survival: correlated patterns and temporal declines. J. Wildl. Manage. 74: 1784-1791. 
Ruhlen, T. D., Abbott, S., Stenzel, L. E., and Page, G. W. (2003) Evidence that human disturbance reduces Snowy Plover chick survival. J. Field Ornithol. 74: 300-304.

Sandercock, B. K. (2003) Estimation of survival rates for wader populations: a review of mark-recapture methods. Wader Study Group Bull. 100: 163-174.

Stenzel, L. E., Page, G. W., Warriner, J. C., Warriner, J. S., George, D. E., Eyster, C. R., Ramer, B. A. and Neuman, K. K. (2007) Survival and natal dispersal of juvenile Snowy Plovers (Charadrius alexandrinus) in central coastal California. The Auk 124: 1023-1036.

Stenzel, L. E., Page, G. W., Warriner, J. C., Warriner, J. S., Neuman, K. K., George, D. E., Eyster, C. R. and Bidstrup, F. C. (2011) Male-skewed adult sex ratio, survival, mating opportunity and annual productivity in the Snowy Plover Charadrius alexandrinus. Ibis 153: 312-322.

U.S. Department of the Interior (2006) Endangered and threatened wildlife and plants: proposed special rule pursuant to Section 4(d) of the Endangered Species Act for the Pacific Coast distinct population of the Western Snowy Plover. Federal Register 58: 12864-20636.

USFWS (2007) Recovery plan for the Pacific Coast population of the western Snowy Plover (Charadrius alexandrinus nivosus). Two volumes. Sacramento, California, USA: United States Fish and Wildlife Service.

Warriner, J. S., Warriner, J. C., Page, G. W. and Stenzel, L. E. (1986) Mating system and reproductive success of a small population of polygamous Snowy Plovers. Wilson Bull. 98: $15-37$.

Watts, C. M., Cao, J., Panza, C., Dugaw, C., Colwell, M. A. and Burroughs, E. A. (2012) Modeling the effects of predator exclosures on a western Snowy Plover population. Nat. Resource Model. 25: 529-547.

White, G. C. (2000) Population viability analysis: data requirements and essential analyses. Pages $288-331$ in L. Boitani and T. K. Fuller, eds. Research techniques in animal ecology: controversies and consequences. New York, USA: Columbia University Press.

Wiedemann, A. M. (1987) The ecology of European beachgrass (Ammophila arenaria). A review of the literature. Portland, Oregon, USA: Oregon Department of Fish and Wildlife Nongame Wildlife Program Technical Report 87-1-01.

Williams, A. J., Ward, V. L. and Underhill, L. G. (2004) Waders respond quickly and positively to the banning of off-road vehicles from beaches in South Africa. Wader Study Group Bull. 104: 79-81.

Wilson, C. A. and Colwell, M. A. (2010) Movements and fledging success of Snowy Plover (Charadrius alexandrinus) chicks. Waterbirds 33: 331-340.

Yalden, D. W. and Pearce-Higgins, J. W. (1997) Density-dependence and winter weather as factors affecting the size of a population of golden plovers Pluvialis apricaria. Bird Study 44: 227-234.

\section{LUKE J. EBERHART-PHILLIPS*1, MARK A. COLWELL}

Department of Wildlife, Humboldt State University, I Harpst Street, Arcata, CA 95521, USA.

${ }^{1}$ Present Address: Department of Animal Behaviour, Universität Bielefeld, Morgenbreede 45, 33615 Bielefeld, Germany.

*Author for correspondence; email: luke.eberhart@uni-bielefeld.de

Received 20 February 2013; revision accepted 26 September 2013 Published online 6 February 2014 